\title{
Estágio supervisionado em Química e os novos moldes da educação: um relato de experiência
}

\author{
Supervised internship in Chemistry and the new forms of education: an \\ experience report
}

\author{
Aniole dos Santos Ferreira ${ }^{1}$ \\ Maíra Souza Machado² \\ Grasiely Faccin Borges 3
}

\begin{abstract}
Resumo
A educação tem sofrido impactos desmedidos em virtude do cenário pandêmico, mas, por intermédio dos recursos tecnológicos, as aulas puderam acontecer modo remoto e, por conseguinte, os docentes tiveram que enfrentar os novos desafios, utilizando as tecnologias digitais. Com as aulas online, as atividades de estágio foram retomadas e adaptadas à nova realidade vivenciada no contexto educacional. Este relato tem como objetivo discutir e analisar as experiências vivenciadas no estágio supervisionado realizado durante a pandemia, por meio do ensino remoto emergencial (ERE), explorando as potencialidades e adversidades desta vivência. O estágio foi realizado por intermédio de atividades síncronas e assíncronas, com o acompanhamento de aulas remotas de Química, em uma escola na capital baiana, através da plataforma Google Meet, com a participação de duas professoras da educação básica em rodas de conversa, abordando temáticas como planejamento pedagógico no ERE e discutindo os desafios e estratégias para novo formato. A partir desta experiência foi possível identificar que as vivências e o fazer pedagógico no estágio proporcionaram o contato direto com o novo contexto educacional, evidenciando a necessidade da constância formativa na trajetória do professor. Nesse itinerário, as atividades realizadas nesse novo formato permitiram também a construção de um novo olhar desses futuros profissionais para a prática docente.
\end{abstract}

Palavras-chave: Ensino remoto emergencial (ERE). Estágio. Aulas remotas. Prática docente.

\begin{abstract}
Education has suffered huge impacts due to the pandemic scenario, including the temporary suppression of classroom activities, but with the use of technological resources, classes returned remotely, therefore teachers had to face new obstacles using

\footnotetext{
${ }^{1}$ Graduanda em Licenciatura Interdisciplinar em Ciências da Natureza, Universidade Federal do Sul da Bahia; Bolsista da Residência Pedagógica/ UFSB-Brasil. E-mail: aniole-ferreira@outlook.com

${ }^{2}$ Doutoranda no Programa de Educação Científica e Formação de Professores da Universidade Estadual do Sudoeste da Bahia (UESB). E-mail: maira.machado1@hotmail.com

3 Centro de Formação em Políticas Públicas e Tecnologias Sociais (CFPPTS) da Universidade Federal do Sul da Bahia (UFSB). E-mail: grasiely.borges@ufsb.edu.br
} 
digital technologies. With online classes, internship activities were resumed and adapted to the new reality experienced in the educational context. In this sense, this report aims to discuss and analyze the experiences lived in the supervised internship carried out during the pandemic, through emergency remote education (ERE), exploring the potential and adversities of this experience. The internship was carried out through synchronous and asynchronous activities, with the monitoring of remote Chemistry classes, in a school in the capital of Bahia, through the Google Meet platform and the participation of two basic education teachers in conversation circles, addressing topics such as planning in the ERE, discussing the challenges and strategies for the new format. From this experience, it was possible to identify that the experiences and the pedagogical practice in the internship provided direct contact with the new educational context, highlighting the need for formative constancy in the teacher's trajectory. In this itinerary, the activities carried out in this new format also allowed the construction of a new look of these future professionals for the teaching practice.

Keywords: Emergency remote teaching (ERE). Internship. Remote classes. Teaching practice.

\section{Introdução}

Atualmente, enfrentamos uma crise sanitária sem precedentes, que afeta todas as estruturas da sociedade. A pandemia de covid-19 chegou trazendo consigo transformações em todas as esferas de nossas vidas. O caos se instalou no mundo e, especificamente, aqui no Brasil, os primeiros casos da doença foram registrados no final do mês de fevereiro de 2020, provocando a paralisação das atividades econômicas não essenciais, sociais e educacionais. O medo causado pela doença desconhecida e as consequências do colapso nos sistemas de saúde público e privado fizeram submergir todo o país em um oceano de incertezas (MATTOS et al., 2021).

A educação sofreu os fortes impactos da pandemia desencadeada pelo vírus SarsCoV-2, causador da doença covid-19. As escolas de todo o País foram paralisadas e as aulas presenciais tornaram-se impossíveis de acontecer, a utilização dos espaços públicos eram inviáveis e foram proibidas. Simultaneamente, medidas de isolamento e distanciamento social compulsório foram adotadas abruptamente como estratégias para diminuir a propagação do vírus. Segundo Mattos et al. (2021), "com o objetivo de frear a disseminação da doença, autoridades de saúde do mundo todo promoveram ações que objetivavam o isolamento social. Iniciava-se, assim, a crise provocada pela disseminação da covid-19" (p. 02).

Com o passar dos dias, com a extensão das medidas de isolamento social e a urgente necessidade de retorno das atividades educacionais no formato remoto mediado por tecnologias digitais, as instâncias nacionais, o Ministério da Educação (MEC) e o Conselho Nacional de Educação ( $\mathrm{CNE}$ ), iniciaram as discussões para regulamentar as atividades em período excepcional. No dia 20 de março de 2020, um decreto legislativo 


\section{-Revista de Iniciação à Docência, v.6, n.2, 2021- Publicação: dezembro, 2021 - ISSN 2525-4332}

estabeleceu o estado de calamidade pública do Brasil (BRASIL, 2020), contudo, somente no dia 18 de agosto, o CNE publicou uma Lei estabelecendo as normas educacionais excepcionais a serem adotadas durante o estado de calamidade pública do País (BRASIL, 2020).

Diante desse contexto, os profissionais da educação precisaram ressignificar sua prática, para atender as novas demandas e enfrentar os desafios que a educação vinha enfrentando. Os professores tiveram de se reinventar e aderir a novas técnicas e metodologias para serem capazes de oferecer suporte adequado para a aprendizagem efetiva dos educandos. Reinvenções foram necessárias no processo de ensino, aprendizagem e avaliação, principalmente nas escolas públicas, visto que, muitos professores e estudantes de todo o Brasil enfrentam dificuldades, limitações de acesso e de disponibilidade a recursos tecnológicos.

E assim, em meio ao cenário pandêmico enfrentado pelo mundo, a comunidade escolar se viu envolta em mudanças, nas quais tiveram que remodelar seus métodos e estratégias de ensino e avaliação. Professores, alunos e seus responsáveis tiveram que encarar as novas adequações para cumprir com as atividades letivas exigidas, mesmo não tendo preparo prévio para lidar com alguns recursos tecnológicos. Portanto, a maioria das instituições e suas equipes docentes tiveram que formular todo um plano que enfrentar a nova realidade (SILVA et al., 2021).

Além da falta de preparo, existe a dificuldade ocasionada pela desigualdade social e financeira. Em meio ao caos pandêmico, tais mazelas, que já assolavam o Brasil, acentuaram-se ainda mais. De acordo com Oliveira et al (2020), o distanciamento social em virtude da pandemia da covid-19 tem salientado a desigualdade social e econômica. Não é raro notar que nem todos os alunos possuem acesso à internet, notebooks e computadores e isso torna o desafio de executar as aulas remotas ainda maior, pois além das dificuldades de adaptação, o professor precisa lidar com os diferentes contextos e níveis sociais que há dentro da sala de aula, e então tentar desenvolver metodologias variadas que alcancem a todos ou quiçá a um número maior de alunos.

Dentre as reformulações para a execução das atividades, está a prática do estágio supervisionado, que não ficou isenta dos reajustes, necessitando também de alterações nas suas formas de organização e execução. O CNE, no dia 28 de abril de 2020, aprovou o parecer CNE/CP n ${ }^{\circ}$ 5/2020 (BRASIL, 2020) que objetivava apresentar a reorganização do calendário escolar e a possibilidade de cômputo de atividades não presenciais para fins de cumprimento da carga horária mínima anual, em razão da pandemia da covid-19.

Com base nas normas e portarias editadas pelos conselhos de educação nas instâncias federal, estadual e municipal, o Parecer CNE/CP n ${ }^{\circ}$ 5/2020 (BRASIL, 2020) permite um novo formato para a efetivação das atividades relacionadas ao estágio supervisionado, no qual a principal recomendação é a substituição do desenvolvimento das atividades práticas dos estágios de forma presencial pela forma remota, utilizando os 
meios e tecnologias digitais de informação e comunicação.

Ainda no ano de 2020, em meio a pandemia da covid-19, com a necessidade do isolamento social, as instituições de ensino tiveram que reelaborar estratégias metodológicas e se adequarem à realidade, tanto na Educação Superior quanto na Básica, para que continuasse sendo ofertada a disciplina de Ensino Supervisionado (BARBOSA et al., 2021).

A Lei de Estágio 11.788/2008 salienta que o mesmo visa preparar educandos que estejam frequentando o ensino regular para o trabalho profícuo, como visto:

[...] estágio é o ato educativo escolar supervisionado, desenvolvido no ambiente de trabalho, que visa à preparação para o trabalho produtivo de educandos que estejam frequentando o ensino regular em instituições de educação superior, de educação profissional, de Ensino Médio, da educação especial e dos anos finais do Ensino Fundamental, na modalidade profissional da educação de jovens e adultos. (BRASIL, 2008).

O desenvolvimento profissional do docente, é um processo que envolve a compreensão das situações concretas dos contextos escolares nos quais eles atuarão. Nessa direção, o estágio supervisionado atua como espaço formativo, possibilitando ao futuro professor a oportunidade de desenvolver habilidades que relacione a teoria e a prática educacional (PIMENTA; LIMA, 2012), permitindo a construção dos conhecimentos necessários para o discernimento das situações que ocorrem em um ambiente escolar.

Ao estagiar, o discente adquiri uma nova visão sobre a educação, na qual passa a compreender a realidade da escola, dos alunos e desenvolver técnicas que possam ser significativas para ambos. É preciso, sobretudo, que o estagiário assuma um papel mais ativo em termos de formação e atuação profissional (GHEDIN; OLIVEIRA; ALMEIDA, 2015).

Neste sentido, para além de um espaço de aproximação com o futuro local de trabalho, o estágio supervisionado é um espaço de desenvolvimento de saberes (TARDIF, 2012), de reconhecimento e aproximação com o chão da escola, de construção e desenvolvimento da autonomia dos futuros professores e dos professores em exercício (supervisores de estágio). Em suma, o estágio caracteriza-se como um campo de conhecimento plural e diverso.

Dessa maneira, frente aos desafios que o educador encontra atualmente, é necessária uma reformulação na maneira de educar e de definir a profissão docente. É preciso que sejam desenvolvidas novas competências, abordagens e referenciais, ou seja, para lidar com os desafios é necessária a inovação das ferramentas e dos profissionais. No presente cenário, o professor que apenas conhece o conteúdo pedagógico, científico e cultural com o qual atua, não é o bastante (CORTE; LEMKE, 2015).

Imbernón (2014) já afirmava que, no futuro, a profissão docente iria se desenvolver em um contexto de grandes mudanças no que se refere às tecnologias e aos avanços do conhecimento, por isso seria essencial que o profissional aprendesse a discernir tais transformações e, principalmente, estivesse aberto às novas adaptações 
para atender às necessidades dos educandos e o contexto de atuação. Destarte, a pandemia fez com que isso se tornasse realidade, os educadores foram forçados a sair de sua zona de conforto, encarando os novos entraves e, consequentemente, transformando sua prática.

Portanto, este relato tem como objetivo discutir e analisar as experiências vivenciadas no estágio supervisionado realizado durante o ensino remoto emergencial (ERE), com o intuito de contribuir para uma reflexão mais profunda sobre as potencialidades e obstáculos na formação docente que emergiram a partir desta nova experiência.

\section{A importância do estágio supervisionado}

Segundo Corte e Lemke (p. 31002, 2015), “o estágio supervisionado proporciona ao futuro profissional docente a chance de conhecer, analisar e refletir sobre seu ambiente de trabalho.", sendo assim, para vivenciar a experiência do estágio, é importante que o aluno esteja bem fundamentado nos conhecimentos teóricos que adquiriu no decorrer da sua formação, afim de que possa experimentar o estágio de modo que complemente a sua construção como educador, desenvolvendo um olhar mais analítico e reflexivo acerca da escola.

De acordo com a Resolução n02/2015 (BRASIL, 2015), o estágio é legalmente uma atividade específica dos cursos de formação de professores, que visa articular a prática com as demais atividades de trabalho acadêmico. Para Pimenta e Lima (2012), é neste espaço que os licenciandos precisam reconhecer a carreira docente e valorizá-la como atividade intelectual, crítica e reflexiva.

Na acepção de Pimenta (2012), o estágio é um local de produção de saberes e experiências, é também um local de aproximação entre escola e universidade, como espaços ricos e produtores de conhecimentos, subjetividades e articulados à prática pedagógica.

Estruturalmente o estágio supervisionado está organizado em três etapas: observação, coparticipação e regência. A última etapa é a fase de ensino que, para Franco (2012), é considerada como:

[...] atividade característica do professor, é uma prática social complexa, carregada de conflitos de valor e que exige opções éticas e políticas. Ser professor requer saberes e conhecimentos científicos, pedagógicos, educacionais, sensibilidade da experiência, indagação teórica e criatividade para fazer frente às situações únicas, ambíguas, incertas, conflitivas e, por vezes, violentas, das situações de ensino, nos contextos escolares e não escolares. É da natureza da atividade docente proceder à mediação reflexiva e crítica entre as transformações sociais concretas e a formação humana dos alunos, questionando os modos de pensar, sentir, agir e de produzir e distribuir conhecimentos na sociedade (FRANCO, 2012, p. 15). 


\title{
-Revista de Iniciação à Docência, v.6, n.2, 2021- Publicação: dezembro, 2021 - ISSN 2525-4332
}

Ou seja, ser professor está além de transmitir os conteúdos de uma grade curricular, está intimamente ligado com a formação do aluno como pessoa, cidadão e agente transformador da própria realidade. Por meio das reflexões proporcionadas pelo educador na sala de aula, é possível estimular novas ideias, opiniões, compartilhamento de saberes.

Corte e Lemke (2015, p. 31003) afirmam que:

\begin{abstract}
Um dos objetivos dos cursos de graduação é o de oferecer os subsídios teóricos e práticos (ou teórico-práticos) necessários ao cumprimento das funções profissionais, de acordo com cada área de conhecimento. Mas, para além disso, é primordial também apresentar aos acadêmicos atividades que promovam a reflexão não só do ponto de vista do conhecimento científico, mas, também, de seu contexto de formação e atuação, dos fundamentos da educação e da dimensão ética, política e ideológica de seu trabalho.
\end{abstract}

Desta forma, prática e teoria na formação docente não é tudo, além disso é preciso estar preparado para lidar com as diversidades de acontecimentos no ambiente escolar a partir de um olhar reflexivo acerca do contexto. Conforme Almeida e Pimenta (2014):

Durante o curso de graduação começam a ser construídos os saberes, as habilidades, posturas e atitudes que formam o profissional. Em períodos de estágio, esses conhecimentos são ressignificados pelo aluno estagiário a partir de suas experiências pessoais em contato direto com o campo de trabalho que, ao longo da vida profissional, vão sendo reconstruídos no exercício da profissão. (p. 73).

Nas licenciaturas, principalmente nas disciplinas de estágio supervisionado, devem ser desenvolvidas atividades que permitam a análise, o conhecimento e a reflexão do trabalho docente, avaliando suas ações, dificuldades e impasses, assegurando uma compreensão mais integral do contexto escolar. Para Pimenta e Lima (2012, p. 15):

Esse conhecimento envolve o estudo, a análise, a problematização, a reflexão e a proposição de soluções às situações de ensinar e aprender. Envolve experimentar situações de ensinar, aprender a elaborar, executar e avaliar projetos de ensino não apenas nas salas de aula, mas também nos diferentes espaços da escola.

Diante do exposto, em meio a todo cenário atual, o estagiário tem o desafio de conseguir assimilar todos os seus fundamentos teóricos que foram edificados em sala de aula, se adaptar aos novos recursos metodológicos, aprimorar seus conhecimentos pedagógicos de maneira que consiga desenvolver suas práticas, aderir às novas ferramentas de trabalho e desenvolver sua formação docente com êxito.

\section{Metodologia}

A experiência relatada ocorreu no componente curricular de Estágio Supervisionado III, na Universidade Federal do Sul da Bahia (UFSB), campus Jorge Amado, localizado na cidade de Itabuna-BA. Após uma longa pausa devido a pandemia, as práticas do Estágio Supervisionado III de Ciências da Natureza foram reiniciadas no período entre 
agosto e setembro de 2020 (calendário acadêmico suplementar excepcional), período este de retomada do componente, pois já havia sido iniciado em março de 2020 e precisou ser interrompido.

No formato interdisciplinar, a UFSB oferta o estágio supervisionado (ES) dividido em sete etapas nas licenciaturas: as etapas um e dois visam introduzir os alunos acerca dos saberes docente e, a partir da observação, os discentes começam a assimilar a teoria com a prática; as etapas três e quatro partem para uma introdução e familiarização do estudante com a regência; as etapas de cinco a sete são voltadas de forma integral para a prática docente, ou seja, a regência em sala de aula. O estudante do curso de Licenciatura Interdisciplinar em Ciências da Natureza (LICN), tem que cumprir a carga horária de 405h de ES, e nesse tempo são feitas atividades de observação e regência nas três disciplinas que pertencem ao grupo das ciências naturais: Biologia, Física e Química. Além disso, dentro dessas horas, é necessário desempenhar $8 \mathrm{~h}$ de regência supervisionada em espaços não formais e 12h no Ensino Fundamental II (UFSB, 2017).

Segundo o Plano Pedagógico da LICN, os cursos de licenciaturas interdisciplinares da UFSB promovem uma formação completa para a docência na Educação Básica, o aluno que concluir a sua graduação será capaz de atuar em sua área de formação, integrando as competências para uma prática interdisciplinar, intercultural, interprofissional e interepistêmica (UFSB, 2016). Ademais, esses futuros docentes poderão promover saberes e práticas nas comunidades com as quais se relacionam, fazendo isso de forma consciente, sensível, ética e qualificada, pois serão capazes de reconhecer a complexidade social e educacional bem como atuar em benefício da transformação da realidade.

A licenciatura interdisciplinar na UFSB objetiva formar docentes com autonomia profissional, incentivando os discentes a serem autores e pesquisadores de sua própria prática, que compreendam a si mesmos como sujeitos em processo de formação permanente, oferecendo uma formação geral, humanística, científica e artística, assim como conhecimentos pedagógicos, tudo de maneira interdisciplinar, possibilitando uma formação profissional que seja integral. Abrigando e valorizando todas as diversidades que compõem a sociedade contemporânea, encorajando e zelando pelo respeito às diferenças nos ambientes em que atuam. A universidade dedica-se para que a acessibilidade seja estabelecida de forma ampla e reflexiva, para que haja um processo de efetiva inclusão. (UFSB, 2016).

O licenciado em Ciências da Natureza e suas Tecnologias é formado para estar apto a desenvolver uma aprendizagem contínua ao longo da vida. De acordo com o professor Paulo Freire, onde ainda há vida, existe inacabamento (FREIRE, 2013), assim, para exercer a função da docência, exige-se um processo de construção que nunca cessa.

É essencial que o discente adquira um olhar crítico sobre a realidade na qual está inserido, a fim de nela intervir, colocando-se como agente transformador "como 
experiência especificamente humana, a educação é uma forma de intervenção no mundo" (FREIRE, 2013, p. 96). Portanto, o professor deve estar capacitado para abordar os conhecimentos das ciências da natureza de forma indissociável dos aportes humanísticos, éticos e solidários que guiam o trabalho e a vida em sociedade.

Visto isso, as atividades da disciplina de estágio foram desenvolvidas da seguinte forma: roda de conversa com a participação de professoras de outras instituições, por do bate-papo além do compartilhamento de experiências, foram feitas abordagens a cerca o planejamento de aula no cenário atual; construção de planejamentos de aula; participação de modo on-line de aulas de química numa escola de educação básica; e por fim, estudo e discussão de referenciais teóricos sobre a formação docente.

\section{Resultados e discussão}

O estágio III foi realizado por intermédio de aulas e atividades remotas, síncronas e assíncronas, utilizando o Google Meet para realização dos encontros síncronos. A professora utilizou a metodologia da sala de aula invertida, por meio do Google Classroom, para organização das atividades.

Bacich e Moran (2018) consideram a aula invertida como uma "estratégia ativa", pois estimula o estudante a assumir um papel ativo. As aulas no formato do ERE e exige que o aluno tenha essa autonomia, seja ativo e protagonista em seu caminhar em busca do conhecimento.

As atividades propostas estavam divididas em três etapas: pré-aula; encontro virtual e pós-aula. No momento da pré-aula, os estudantes deveriam assistir a vídeos indicados, e realizar a leitura de artigos; no encontro virtual, o espaço era para socialização das ideias e a professora mediava o processo organizando os conteúdos; e no pós-aula, algumas atividades foram propostas, como por exemplo a participação no fórum do Classroom, elaboração de planos de aula (contendo objetivos conceituais, procedimentais e atitudinais) e escrita do relatório de estágio.

Mesmo ainda sujeitos às desvantagens ocasionada pelo isolamento social, esse novo modelo de ensino permite o rompimento das barreiras do espaço geográfico, possibilitando a realização das atividades propostas, contando com a presença de professores de outras instituições, que talvez antes, de modo presencial, não seria possível devido às inúmeras circunstâncias, como por exemplo: a incompatibilidade de horários disponíveis na agenda, aliada à distância e aos custos de deslocamento. Em continuidade, duas educadoras ${ }^{4}$ da educação básica foram convidadas para participar de uma roda de conversa proposta pela professora do componente curricular, onde na oportunidade foi realizada uma discussão sobre a importância do planejamento, como construí-lo, como é o seu processo de desenvolvimento, tanto na parte teórica como na prática, seja ela de modo virtual ou presencial.

\footnotetext{
${ }^{4}$ Os nomes das educadoras foram suprimidos por questões éticas.
} 
Em dias alternados, as docentes da educação básica convidadas compartilharam com os alunos de estágio suas trajetórias nesse novo formato da educação, como estavam se organizando e preparando seus planejamentos para contemplar os objetivos educacionais dentro do formato do ERE. Abordaram no bate-papo, quais eram os desafios mais constantes vivenciados nesta nova experiência, quais as estratégias mais utilizadas, como estava sendo o retorno dos estudantes nas atividades propostas, entre outras questões.

Em meio a nova realidade da educação, os profissionais se depararam com vários desafios, dentre eles o planejamento e, consequentemente, a avaliação. A indagação de muitos professores das unidades escolares ainda era: Como planejar uma aula virtual? Quais recursos usar? Como avaliar a aprendizagem dos alunos? Estas indagações emergem a partir da ausência do contato pessoal com os educandos, sendo esta uma das principais limitações do ambiente virtual.

A partir das discussões realizadas, uma questão importante foi notada, o docente já não consegue desenvolver apenas um planejamento e uma avaliação, pois existem alunos que não possuem acesso à internet e nem possuem um ambiente propício para estudar e assistir as aulas, por conseguinte, os métodos de planejamento e avaliação para estes não podem ser os mesmos utilizados para os que possuem acesso. Portanto, existem estes detalhes que o educador deve estar atento na hora de planejar e avaliar. Neste novo momento, não há mais a possibilidade de uma uniformização do planejamento, Gatti (2020) afirma que é preciso "[...] deixar velhos hábitos, buscar novos sentidos para a educação escolar e novos caminhos" (p. 37); de tal maneira, o ensino baseado no modelo tradicional em que o professor utilizava somente um método para todas as suas aulas, não é mais viável.

O planejamento é considerado como passo decisivo para a melhoria do trabalho docente, pois é nesta etapa em que se identifica as realidades e dificuldades dos alunos (PIMENTEL; FIGUEIREDO, 2010).

Segundo Lopes (1991, p. 43) "[...] o bom plano de ensino se traduzirá pela ação pedagógica direcionada de forma a se integrar dialeticamente ao concreto do educando, buscando transformá-lo", ou seja, de alguma maneira os conteúdos devem estar entrelaçados com a experiência de vida dos educandos. No entanto, muitas vezes o professor planeja suas atividades sem estabelecer relações com a realidade vivida pelo aluno, o que torna sua aula pouco atrativa e pouco proveitosa. Por isso, é necessário que o educador esteja atento para realizar essa interligação entre contexto e conteúdo.

No cenário pandêmico existe uma variabilidade de realidades, alguns alunos possuem condições financeiras confortáveis, porém outros estão em completa vulnerabilidade financeira, social, e sofrendo com a desestrutura familiar, tais fatos já se 


\title{
-Revista de Iniciação à Docência, v.6, n.2, 2021- Publicação: dezembro, 2021 - ISSN 2525-4332
}

faziam presentes na sala de aula, no entanto, com o ensino remoto 5 o professor acabam lidando com essas realidades de forma mais direta e expressiva, já que o ambiente de realização das atividades do cotidiano tornou-se o mesmo ambiente de estudo.

Vasconcellos (2000) nos esclarece que:

[...] o planejamento enquanto construção-transformação de representações é uma mediação teórica metodológica para ação, que em função de tal mediação passa a ser consciente e intencional. Tem por finalidade procurar fazer algo vir à tona, fazer acontecer, concretizar, e para isto é necessário estabelecer as condições objetivas e subjetivas prevendo o desenvolvimento da ação no tempo. (p. 79)

Portanto, o planejamento é uma ação conjunta, na qual a prática deve sempre estar mediada com a metodologia, e assim promover a construção da aprendizagem e o engajamento do aluno nas aulas, sem esquecer do contexto que está inserindo o educando. Hoje no ERE, o planejamento deve estar vinculado às tecnologias digitais como forma do professor estabelecer situações de aprendizagem (BACICH; MORAN, 2018).

O planejamento é essencial, pois por intermédio dele é possível traçar e organizar as ações e atividades que irão ser desenvolvidas, e a partir disso ir alinhado os conteúdos com as práticas em sala de aula. Para Vasconcellos (2000):

[...] planejar é antecipar mentalmente uma ação ou um conjunto de ações a serem realizadas e agir de acordo com o previsto. Planejar não é, pois, apenas algo que se faz antes de agir, mas é também agir em função daquilo que se pensa. (p.79)

O ato de planejar no processo de ensino é essencial para a formação de cidadãos críticos, compromissados com a transformação da sociedade para a melhoria da qualidade de vida, então o planejamento deve possuir um caráter integrador, ou seja, participativo, discursivo e problematizador, como enfatiza Lopes (1991):

\begin{abstract}
Essa abordagem integradora, com efeito, é que proporcionará um ensino voltado para a formação de pessoas críticas, questionadoras e atuantes. Entendemos que uma educação integradora, onde professores e alunos produzam conhecimentos a partir da participação da escola na sociedade e viceversa, estará formando efetivamente um educando com possibilidades de contribuir concretamente para a transformação da sociedade (p. 50)
\end{abstract}

Portanto, o planejamento não visa apenas a execução do conteúdo, mas também deve se importar com a formação completa do aluno, de modo que o conhecimento adquirido em sala, seja ela virtual ou presencial, transponha o ambiente escolar e chegue até a sua comunidade, para que o educando a partir de sua aprendizagem se torne um agente transformador na sociedade.

E partindo para a parte prática do desenvolvimento das atividades da disciplina,

\footnotetext{
5 Conforme Morais et al. (2020) o ensino remoto permite o auxílio da tecnologia para mediar a escolarização, mantendo o distanciamento entre o docente e o discente.
} 


\section{-Revista de Iniciação à Docência, v.6, n.2, 2021- Publicação: dezembro, 2021 - ISSN 2525-4332}

com base nas discussões e no estudo do referencial teórico Zabala (2014), os alunos desenvolveram planos de aula pensando nas características trazidas pelo autor e que atendesse o atual contexto no qual a educação está inserida. O tema do planejamento da aula foi de livre escola do discente, desde que estivesse relacionado com a matéria de Biologia, e voltado para alguma das séries do ensino médio. O plano continha as características básica: (objetivo, estratégias didáticas, avaliação, resultados esperados etc.), no entanto o conteúdo estava dividido em partes.

Segundo Zabala (2014), os conteúdos possuem quatro tipologias: factuais, referem-se ao conhecimento de fatos, as informações em si; conceituais, referem-se ao conhecimento de conceitos enquanto conjunto de fatos, objetos, símbolos e afins, nesse processo inclui a abstração, compreensão, reflexão, análise e comparação; procedimentais, está relacionado ao aprender a fazer, e ao desenvolvimento de atividades que sejam direcionadas para o alcance dos objetivos; e os atitudinais que é focado em questões de valores, normas e atitudes, envolvendo reflexão e posicionamento.

Desta forma, o conteúdo não é apenas um conjunto de informações sistematizadas e organizadas sobre determinado assunto, mas garante um planejamento com intencionalidade e reflexão sobre aquilo que é trabalhado em sala de aula. Com base dessa perspectiva os planos de aula foram construídos, moldando-se a realidade das aulas remotas, atrelando o cotidiano com o conteúdo, e objetivando uma formação integral do aluno.

E a partir da reflexão de tais definições, os alunos desenvolveram seus os planos de aula, na socializaram com a docente e os demais colegas, compartilharam a experiência da construção do plano e as dificuldades encontradas durante a elaboração. A docente da disciplina, de maneira construtiva, teceu comentários que traziam algumas correções necessárias e elogios destacando os pontos de êxito.

Também houve a participação, de modo online, de uma aula de Química ministrada por uma das professoras convidadas, em turmas do segundo ano do ensino médio de uma escola da capital baiana. Esse momento foi muito importante, pois de maneira prática, observou-se como as aulas remotas foram desenvolvidas, como a docente organizou a dinâmica da aula nos moldes virtuais e utilizou as ferramentas tecnológicas dentro do seu planejamento, contemplando os conteúdos e a participação dos alunos.

Ficou claro, na experiência vivenciada, que uma aula remota não possui a mesma dinâmica da aula presencial, são ambientes diferentes, com potencialidades e limitações distintas, por isso os educadores devem buscar novos recursos e métodos para atender as demandas emergentes deste novo contexto e dos alunos.

Foi possível identificar algumas dificuldades no exercício da docência neste novo formato. Observou-se que, mesmo aqueles professores que já utilizavam as tecnologias digitais como apoio ao ensino presencial, encontraram dificuldades para se adaptarem ao 
ensino remoto, como por exemplo a infraestrutura inadequada em suas casas, a ausência de uma formação específica para exercer a docência de maneira remota, e falta de afinidade com os recursos tecnológicos.

Segundo Imbernón (2014), o exercício da docência por si só engloba muitas complexidades e funções, e em meio do cenário pandêmico surgem mais questões. Atualmente, um dos grandes desafios é fazer com que o aluno interaja com o educador e colegas durante as aulas remotas nos momentos síncronos, de forma que seja possível ajudá-lo na construção do conhecimento e avaliar sua aprendizagem. De acordo com Imbernón (2014, p. 14):

O contexto em que trabalha o magistério tornou-se complexo e diversificado. Hoje, a profissão já não é a transmissão de conhecimento acadêmico ou a transformação do conhecimento comum do aluno em um conhecimento acadêmico. A profissão exerce outras funções: motivação, luta contra a exclusão social, participação, animação de grupos, relações com estruturas sociais, com a comunidade... E, é claro, requer uma nova formação: inicial e permanente.

A pandemia impôs grandes dificuldades tanto aos professores, quanto aos estudantes. Como manter os vínculos com os alunos sem estar no mesmo espaço físico? Como utilizar as tecnologias da informação e comunicação (TIC) para aprender e ensinar? Como utilizar estas tecnologias digitais em rede na educação em um País tão desigual quando o assunto é acesso à internet e conexão de qualidade? Estas são perguntas que nos inquietam e nos fazem pensar sobre novas educações (PRETTO, 2005), ou seja, outras possibilidades que possam superar o modelo tradicional e bancário de educação (FREIRE, 2011).

Segundo uma pesquisa do Instituto Península (2020), 88\% dos professores nunca tinham dado aula de forma remota e $83,4 \%$ não se sentem preparados. Tudo ainda é muito novo e requer muita dedicação para ser realizado, de modo que a aprendizagem não seja somente proporcionada, mas também alcançada. O obstáculo do educador agora é abrir caminhos para a aprendizagem de maneira remota, sem o envolvimento direto dos educandos e sem poder fazer o mesmo acompanhamento que é possível no formato presencial.

Envoltos a tantos questionamentos e obstáculos, para os estagiários, notar o desenvolvimento de maneira harmônica e produtiva na sala de aula virtual foi o ponto mais importante da experiência, a adaptação dos alunos e da docente, a maneira como conseguiam desenvolver a aula a partir de estratégias simples, como a resolução coletiva de questões durante a explanação do conteúdo abordado e, a partir disso, diagnosticar se os discentes estavam conseguindo compreender o conteúdo.

A pesquisadora Edméa Santos (2020) afirma que o ensino remoto tem deixado suas marcas, permitindo a continuidade da rotina de estudos, encontros afetuosos e a criação de boas dinâmicas, mas também podendo causar exaustão e desgaste. Pensando nisto, a educação mediada por tecnologias deve promover e propiciar espaços 


\section{-Revista de Iniciação à Docência, v.6, n.2, 2021- Publicação: dezembro, 2021 - ISSN 2525-4332}

colaborativos e participativos. Os professores devem compreender os aspectos que caracterizam este novo ambiente, como o que define o desenho didático, utilizar estratégias diferenciadas, interfaces e plataformas digitais, bem como de que maneira elaborar as rubricas de avaliação, saberes docentes para a docência de modo online, entre outros. Tais aspectos permeiam uma nova cultura que já se instalou no cenário educacional.

Na educação on-line, definida por Santos (p. 5663, 2009) como "conjunto de ações de ensino-aprendizagem ou atos de currículo mediados por interfaces digitais que potencializam práticas comunicacionais interativas e hipertextuais", está profundamente ligada a utilização das redes e contando com o suporte das tecnologias, abrangendo a colaboração, comunicação e envolvimento nas atividades (MIRANDA, 2005), este planejamento é caracterizado como desenho didático, com características próprias do ambiente virtual, como sons, textos e etc.

Dessa maneira, na educação online a prática educativa precisa e deve estar atrelada às nuances da cibercultura para que as aulas não fiquem "massivas nem maçantes" (PIMENTEL; CARVALHO 2020). É, portanto, nesta direção que pesquisadores (SANTOS, 2019; PIMENTEL; CARVALHO, 2020) indicam que a elaboração do desenho didático seja inspirada nos princípios da cibercultura, pois na sociedade contemporânea, em que os estudantes são considerados nativos digitais, é preciso que haja uma reconfiguração na educação formal, em especial a partir da vivência no ensino remoto.

De modo geral, o objetivo da educação, seja no formato presencial, online ou híbrido $^{6}$, não é apenas de formar bons estudantes, bons profissionais, mas sim cidadãos conscientes, ativos e críticos (FREIRE, 2013). Zabala (p. 256, 2014) reitera que "[...] podemos entender que a função social do ensino não consiste apenas em promover e selecionar os 'mais aptos' para a universidade, mas que abarca outras dimensões da personalidade".

Diante desse contexto desafiador de distanciamento social, é importante a promoção, mesmo que de maneira remota, de espaços de aprendizagem, trocas experiências, diálogo, criação e escuta, auxiliando e permitindo aos estudantes da educação básica ou do ensino superior, a formação intelectual e humana.

No atual cenário, é tempo de repensar as estruturas educacionais tradicionais. É preciso forjar novos espaços que superem estruturas positivistas e cartesianas. Como disse Gatti (2020):

[...] o impacto repentino das mudanças de rotinas no trabalho, no estudo, nas relações, nas necessidades, nesses tempos de isolamento social, provocou rupturas com hábitos arraigados e reflexões sobre o que é essencial e o que é supérfluo. (p. 39)

\footnotetext{
${ }^{6}$ Segundo Bacich (2016), o ensino híbrido é a mescla de diferentes ambientes de ensino-aprendizagem, que possibilita ao aluno a autonomia.
} 
Desse modo, o que realmente tem significado na aprendizagem de cada estudante é aquilo que ele conseguiu assimilar, é aquilo que foi expressivo para ele. Sendo assim, a educação escolar, bem como muitas das suas definições, precisarão ser repensadas no período pós-pandemia (GATTI, 2020).

E por fim, para a conclusão da disciplina de estágio, a estratégia utilizada foi a leitura e discussão de autores que levantam questões relevantes para a formação docente. Lemos e discutimos obras como o livro de Paulo Freire "Pedagogia da Autonomia" e Antoni Zabala "Prática educativa: Como ensinar", e por intermédio dessas leituras, desenvolveu-se o debate sobre o exercício da docência dentro dos novos moldes que a educação tem tomado, quais caminhos seguir tanto no aspecto individual como também no coletivo, sobre qual deve ser o professor a conduta em sala de aula, sendo aquele que busca constantemente o aperfeiçoamento e evolução na sua práxis.

Vivenciar o ERE trouxe oportunidade de refletir e discutir sobre as potencialidades do ambiente virtual bem como as suas limitações, construir conhecimentos importantes e correspondentes aos objetivos do estágio, fazendo com que a experiência se torna-se excepcional. Sendo assim, a experiência deixou sua marca, contribuindo de forma excepcional para a formação dos estudantes.

\section{Considerações finais}

A pandemia trouxe consigo muitas incertezas, mudanças, e desafios, mas também nos abriu um leque de possibilidades. Seus impactos ficarão marcados, a transformação que houve no mundo jamais será esquecida. A educação, como todas as outras coisas, se reinventou, lutou para seguir em frente, e dá continuidade na sua missão. Como todo processo de descoberta, existiram muitos erros que serviram de aprendizado, mas também existiram acertos que nos abriram os olhos para aquilo que há de positivo e proveitoso na nova experiência da docência de maneira remota.

Os resultados da experiência vivenciada e relatada demostraram que o estágio supervisionado, de fato, contribui para a formação de professores de forma significativa, oportunizando a reflexão e inovação da práxis educacional.

A educação exige transformação e, através do estágio, é possível afirmar que essa transformação deve partir dos próprios profissionais, que necessitam sempre estar preocupados em avaliar e repensar suas práticas, modificando-as em busca de aprimoramento e adquirindo conhecimentos cada vez mais significativos, e que os auxiliem no desenvolvimento da sua profissão.

Os momentos de ensino e aprendizagem e o fazer pedagógico na prática do estágio supervisionado III, proporcionaram o contato direto com o novo contexto educacional, provando que no universo da educação o professor deve estar sempre preparado para os desafios. 
Por fim, o estágio vivenciado neste novo formato permitiu a construção de um novo olhar desses futuros profissionais. Evidenciou ainda a figura do professor não somente resumida ao ensino e à transmissão de conhecimentos, revelou a necessidade de uma formação constante deste profissional, mostrou os potenciais e as limitações do ambiente virtual de aprendizagem, e a necessidade de uso das tecnologias digitais no contexto educacional para o período pós pandemia.

Destarte, as dificuldades a cada desafio, teve o potencial para tornar a criação possível, pois a cada obstáculo nos reinventamos. A inovação muitas vezes vem a partir da experiência de vivenciar o caos e assim criar zonas de possibilidades e potencialidades.

\section{Referências}

ALMEIDA, M. I.; PIMENTA, S. G. Estágios supervisionados na formação docente. São Paulo: Cortez, 2014.

BACICH, L. Ensino híbrido: relato de formação e prática docente para a personalização e o uso integrado das tecnologias digitais na educação. Simpósio Internacional de Educação e Comunicação-SIMEDUC, n. 7, 2016.

BACICH, L.; MORAN, J. (org.). Metodologias ativas para uma educação inovadora: uma abordagem téorico-prática. Porto Alegre: Penso, 2018.

BARBOSA, E. P.; SANTOS, J. L. B. DOS; NETO, J. G. DA C.; LIRA, S. M. DE; MONTEIRO, T. R. R. Ensino Supervisionado no ensino remoto de Geografia na ECIT Maria Honorina Santiago - Santa Rita/PB. Cadernos de Estágio, v. 2, n. 2, p. 172-183, 16 abr. 2021.

BRASIL. Resolução CNE/CP nº 02, de 01 de julho de 2015 - Diretrizes Curriculares Nacionais para a formação inicial em nível superior e para a formação continuada MEC: Brasília - DF, 2015. Disponível em:

<http://portal.mec.gov.br/index.php?option=com_docman\&view=download\&alias=17719res-cne-cp-002-03072015\&category_slug=julho-2015-pdf\&ltemid=30192 >.Acesso em 19 de agosto de 2021.

BRASIL. Lei $\mathbf{n}^{\circ} \mathbf{1 1 . 7 8 8} 25$ de setembro de 2008. Disponível em: <http://www.planalto.gov.br/ccivil_03/_ato2007-2010/L/lei/l11788.htm>. Acesso: em 10 de maio de 2021.

BRASIL. Ministério da Educação. Conselho Nacional de Educação. Parecer CNE/CP 5, de 28 de abril de 2020. Reorganização do Calendário Escolar e da possibilidade de cômputo de atividades não presenciais para fins de cumprimento da carga horária mínima anual, em razão da Pandemia da COVID-19. Brasília: DF, 2020. D.O.U. de 01/06/2020, Seção 1, Pág. 32. Disponível em:

<http://portal.mec.gov.br/index.php?option=com_docman\&view=download\&alias=145011 -pcp005-20\&category_slug=marco-2020-pdf\&ltemid=30192 >.Acesso em: 15 de abril de 2021.

CORTE, A. C. D. ; LEMKE, C. K. O estágio Supervisionado e sua importância para a formação docente frente aos novos desafios de ensinar. Educere, Brasília, v. 31, n. 3, p. 31002-31010, 2015

FRANCO, M. A. R. S. Pedagogia e prática docente. São Paulo: Cortez, 2012 
FREIRE, P. Pedagogia da autonomia: saberes necessários à prática educativa. 47. Ed. Rio de Janeiro: Paz e Terra, 2013.

FREIRE, P. Pedagogia do oprimido. 50. ed. São Paulo: Paz e Terra, 2011.

GATTI, B. Possível reconfiguração dos modelos educacionais pós pandemia. Estudos avançados, v. 34, n.100, 2020.

GHEDIN. E.; OLIVEIRA E. S.; ALMEIDA, W. A. Estágio com pesquisa. São Paulo: Cortez, 2015.

IMBERNÓN, F. Formação docente e profissional: formar-se para a mudança e a incerteza. São Paulo: Cortez, 2014.

LOPES, A. O. Planejamento do ensino numa perspectiva crítica de educação. In: VEIGA, Ilma; PASSOS, A. Repensando a didática. 5 ed. Campinas, SP: Papirus, 1991.

MATTOS, E. A. DE; SILVA, J. P. A. DA; RABELLO, P. I. R.; QUEIROZ, D. DE M.; NASCIMENTO, W. E. As professoras de ciências naturais e o ensino remoto na pandemia de COVID-

19. Cadernos de Estágio, v. 2, n. 2, p. 105-118, 16 abr. 2021.

MIRANDA, L. Educação online: interação e estilos de aprendizagem de alunos do ensino superior numa plataforma web. Tese de doutoramento em Educação (Área do Conhecimento de Tecnologia Educativa. (Tese de doutorado). Braga: Universidade do Minho 2005.

MORAIS, I. R. D., Garcia, T. C. M., Rêgo, M. C. F. D., Zaros, L. G., \& Gomes, A. V. G. Ensino remoto emergencial: orientações básicas para elaboração do plano de aula. Natal: SEDIS/UFRN, 2020.

OLIVEIRA, A. M. D. DE; AZEVEDO, D. K. S. DE; VIANA, F. R. A educação especial na perspectiva da educação inclusiva em tempos de pandemia. Cadernos de Estágio, v. 2, n. 1, p. 58-60, 23 dez. 2020.

PENÍNSULA, I. Sentimento e percepção dos professores brasileiros nos diferentes estágios do Coronavírus no Brasil. 2020. Disponível em:

<https://www.institutopeninsula.org.br/>. Acesso em 10 maio de 2021

PIMENTA, S. G. LIMA, M. S. L. Estágio e docência. São Paulo: Cortez, 2012.

PIMENTA, S. G. O estágio na formação de professores: unidade, teoria e prática? São Paulo: Cortez, 2012.

PIMENTEL, M.; CARVALHO, F. S. P. Princípios da Educação Online: para sua aula não ficar massiva nem maçante! SBC Horizontes, maio 2020. ISSN 2175-9235. Disponível em: <http://horizontes.sbc.org.br/index.php/2020/05/23/principios-educacao-online>. Acesso em: 04 junho de 2021.

PRETTO, N. L. (org.). Tecnologia e novas educações. Salvador/Bahia: Edufba, 2005. v. 1, $230 \mathrm{p}$.

SANTOS, E. Educação online para além da EAD: um fenômeno da cibercultura. In: Actas do $X$ congresso internacional galego-português de psicopedagogia. Braga: Universidade do Minho. 2009. p. 5658-5671.

SANTOS, E. Pesquisa-formação na cibercultura. Teresina: EDUFPI, 2019. 
SANTOS, E. O.; SILVA, M. Desenho didático para educação on-line. In: Revista Em Aberto, Brasília, v. 22, n. 79, p. 105-120, jan. 2009.

SANTOS, E. O. EAD, palavra proibida. Educação online, pouca gente sabe o que é. Ensino remoto, o que temos. Notícias, revista docência e cibercultura, agosto de 2020, on-line. ISSN: 2594-9004. Disponível em: <https://www.e-publicacoes.uerj.br/index.php/redoc/announcement/view/1119>. Acesso em: 26 de ago. 2021.

SILVA, J. O. DA; RODRIGUES, L. J. F.; SOUZA, M. C. S. DE; BRANDÃO, N. C. Adaptação do ambiente escolar para o ensino remoto: a visão de um professor de física. Cadernos de Estágio, v. 2, n. 2, p. 127-135, 16 abr. 2021.

SILVA, M. Sala de aula interativa. São Paulo: Quartet, 2000.

TARDIF, Maurice. Saberes docentes e formação profissional. Editora Vozes Limitada, 2012.

TORMENA, A. A.; FIGUEIREDO, J. A. PLANEJAMENTO: a importância do plano de trabalho docente na prática pedagógica. Cadernos PDE, 2010.

UFSB. Orientações $\mathbf{n}^{\circ}$ 2/2017. Dispõe sobre orientações específicas acerca do Estágio Supervisionado no âmbito da Licenciatura Interdisciplinar em Ciências da Natureza e suas Tecnologias. Itabuna, 2017.

UFSB. Plano pedagógico de curso licenciatura interdisciplinar em ciências da natureza e suas tecnologias. Itabuna, novembro de 2016.

VASCONCELLOS, C. Planejamento projeto de ensino-aprendizagem e projeto políticopedagógico. 7 ed. São Paulo: Libertad, 2000.

ZABALA, A. A prática educativa: como ensinar. Porto Alegre: Penso, 2014. 